\title{
Building collaboration through shared actions: The experience of the Global Network for Disaster Reduction
}

\author{
Author: \\ Terry Gibson ${ }^{1}$

\section{Affiliation:} \\ ${ }^{1}$ Global Network of Civil \\ Society Organisations for \\ Disaster Reduction (GNDR), \\ Teddington, United Kingdom \\ Correspondence to: \\ Terry Gibson \\ Email: \\ terry.gibson@globalnetwork- \\ dr.org

\section{Postal address:} \\ GNDR 100 Church Road, \\ Teddington, TW118QE, \\ United Kingdom \\ Dates: \\ Received: 24 Apr. 2012 \\ Accepted: 06 Aug. 2012 \\ Published: 04 Oct. 2012 \\ How to cite this article: \\ Gibson, T., 2012, 'Building \\ collaboration through shared \\ actions: The experience \\ of the Global Network for \\ Disaster Reduction', Jàmbá: \\ Journal of Disaster Risk \\ Studies 4(1), Art. \#48, \\ 6 pages. http://dx.doi.org/ \\ 10.4102/jamba.v4i1.48
}

C 2012. The Authors. Licensee: AOSIS OpenJournals. This work is licensed under the Creative Commons Attribution License.
This article asks how the emergent Global Network for Disaster Reduction has built collaboration and impact. Observation of the network's journey nuanced the researcher's initial hypothesis in marked ways. A 'reflective practitioner' perspective is adopted, locating action within two relevant theoretical frameworks to aid understanding and define future progress. Development showed an early emphasis on a 'community of practice' model. However, this appeared ineffective in creating the intended collaboration and led to the recognition of the power of shared action. This observation is framed within the thinking of Freire (1996) on action and reflection as a means of empowerment. The political dimension of the network's activity is recognised, and is related to Gaventa's (1980) thinking on the creation of political space. The article attempts to show that combining cycles of action and reflection in the network's activity (i.e. creating a practitioner focus) with a wider investigation of relevant literature and thinking can be helpful in framing understanding and determining future strategy. It concludes by suggesting that a proposed framework of 'communities of praxis' may have a broader application in the development of networks.

\section{Introduction}

Networks are a phenomenon of our time, whether in the case of practitioner and other professional networks or of the burgeoning social networks industry (see for example Waddell 2009). Away from the world of Facebook, Twitter and other social platforms, a widely used professional network model is that of 'Communities of Practice', which has been widely applied in industry, education and international development (Wenger 2002). Its emphasis on the accumulation of practice-based knowledge within practitioner communities sits very naturally with the opportunities created by the information and communication technology (ICT) revolution.

As a consequence, the term 'communities of practice' has become synonymous with a wide range of collaborative activities, many of which Etienne Wenger (2002), the originator of the term, would hardly recognise. For Wenger the architecture of such communities was quite specific; it was developed from a study of how apprentices learn. It was constructed around a community of core members, allowing for legitimate peripheral participation focused on the members' practice in a particular knowledge domain. However, in the 'connected' 21st century, or at least in the developed North, this architecture has been applied in diverse ways to distributed communities through the use of email, discussion forums, websites, document stores and rich media channels such as web conferences.

This combination of communities and communication opens up the possibility of new, liberating and democratised information and knowledge channels - much as channels such as YouTube and Twitter have altered the traditional hierarchy of professional broadcasting and news channels. This article takes that possibility a stage further, by asking whether such emerging 'connected communities' can underpin a new 'Freirian revolution' in which Freire's goal of the conscientisation of the oppressed is achieved transnationally and electronically, rather than through his face-to-face 'culture circles' (Freire 1996).

\section{Pedagogy of the Oppressed}

The Brazilian educator and activist Freire published his widely referenced and acknowledged Pedagogy of the Oppressed in 1970. He used the term 'praxis' in relation to his principles of action and reflection in culture circles, and this thinking has influenced many subsequent participative approaches:

This pedagogy makes oppression and its causes objects of reflection by the oppressed, and from that reflection will come their necessary engagement in the struggle for liberation. (Freire 1996:30)

However, this author is as guilty as others of drawing on Freire's broad themes of 'participation' and what he called 'conscientisation' (translated from the Portuguese term conscientização, which 
means 'to learn to perceive social, political and economic contradictions and to take action against oppressive elements of them' (Freire [1996:90]) without paying close attention to what he actually said. Therefore in this article and the practitioner experience it reflects, the voice of Freire is allied to the exploration of his core idea of 'praxis' - action and reflection - as it bears on this attempt to apply his concepts in an electronically connected 'distributed network' setting.

Freire's perspective on learning sits within Kolb's (1984) model of experiential learning, which he expressed as a cyclical process (although he in turn attributed it to thinkers such as Dewey, Lewin and Piaget (Kolb 1984:5, 8). This view of learning starts with action or experience, which leads to reflection and the synthesis of a new understanding. In its turn this new understanding leads to a revised approach to action. Experiential learning is based on a view of knowledge which is 'pluralist' rather than 'positivist'. Pluralism is the view that knowledge is created as a social process within groups or communities, rather than being universal in nature (see for example case studies of social learning in Wals 2007).

This view of knowledge may be difficult for 'hard' disciplines such as the natural sciences to accept, concentrating as they do on narrowly focused 'cause and effect' processes, although even in the realms of technology social learning processes have an increasing role, for example in the knowledgecreation processes of 'communities of practice' (Wenger 2002). These and other shared learning approaches recognise that practical, 'on the job' knowledge is dynamic in nature.

In social groups and interactions, shared experiential understanding can be seen as generating knowledge in an even deeper sense: it defines the world of that social group. Habermas (1987) distinguishes these worlds as 'lifeworlds' and sees a tension between this shared understanding and attempts of the external overarching 'system' to exercise control and power (or in his terms to 'colonise' the lifeworld). This tension between knowledge and power was Freire's entry point. He argued that in practice the views of the powerful (or 'oppressors' in his terms) dominated the views of the 'oppressed'. Knowledge was used as a way of exerting power. In his view the knowledge of particular groups the 'authorities' - was afforded a value and importance which allowed it to be imposed on the oppressed, therefore maintaining the status quo. This meant that the poor and oppressed often became passive and did not even question the conditions of their existence.

Freire challenged this positivist perspective and the accompanying 'banking' view of knowledge in which a dominant and institutionally accepted body of knowledge is simply imparted to passive recipients. In its stead he developed the principle of 'conscientisation' where through active reflection on experience (Kolb's 'learning cycle') - participants in his culture circles developed their own understanding of their situation and therefore of their options for action. Action and reflection were therefore closely related - the principle of 'praxis'. This analysis has been widely used in challenging 'positivist' approaches to development in which external 'experts' dominate even supposedly 'participative' situations. Chambers (1997) for example asks: 'Whose reality counts?' A collection of papers called 'Participation: the new tyranny?' (eds. Cooke \& Kothari 2001) highlights the ways that a positivist approach leads to so-called participative approaches simply being used to co-opt groups of people according to the agenda of the external 'experts'.

Freire's founding principle of knowledge creation based on shared cycles of action and reflection, and the consequent possibility of enabling groups to take control of their own understanding and action are themes of particular interest in the present article.

\section{Building a network}

It was with an interest in addressing the new possibilities which electronic communications offer to networks that the author took on the role of project manager and communications specialist for an emergent South-based network, The Global Network of Civil Society Organisations for Disaster Reduction (GNDR).

The network was founded in 2007 as a civil society response to the perceived limitations of the United Nations' (UN) ten year plan of action for Disaster Risk Reduction. This had been framed in 2005 as a programme for progress (The Hyogo Framework for Action - UNISDR 2005), with a focus on opportunities for reducing vulnerability and increasing the resilience of communities in the face of natural disasters. However, it was generally felt by the founders of GNDR that the institutional and 'top-down' character of the UN meant that while policies were being constructed and agreed on with member nations, practical application as well as consultation was lacking at community level, which is where disasters strike.

The specifications for the role of project manager placed an emphasis on network building, on communication and, specifically, on the application of a social networking model to develop and respond to 'social demand'. This suggested rich opportunities for building a 'community of practice' and capitalising on the new communications tools which ICT offers.

The main focus of the network's activity was to be a project called 'Views from the Frontline' which aimed to achieve independent monitoring of the progress of the UN programme through community-level consultation and surveying on a large scale in more than forty countries. The project was organised around activities in ten regions across Latin America, Africa and Asia. In each region a coordinating organisation led several national coordinating organisations who took the lead in their country, coordinating the work of several participating organisations in each country These organisations ranged from the national offices of international Non-governmental organisations (NGOs), where specialist 
Disaster Risk Reduction staff would typically be involved, to smaller national and local NGOs who were often working on a range of development and humanitarian programmes. In the 2009 iteration of the project the entire network of over 400 organisations, NGOs working in 40 countries in Latin America, Africa and Asia, gathered more than 7000 individual face-to-face surveys of perceptions of progress on disaster reduction from respondents at community level. These surveys were then analysed to form the basis of a report delivered to the UN biennial progress assessment (The UNISDR Global Platform for Disaster Risk Reduction). The project was ambitious, untested, and had very tight deadlines (GNDR 2009).

\section{Learning processes}

Just over a year later (in January 2010), after an intense period of work, network members from many of GNDR's participating organisations gathered for a Global Workshop to review what had been achieved in the Views from the Frontline project, and to consider their next steps. The detailed implementation and outcomes of the project are documented elsewhere (GNDR 2009; Gibson 2010). It is sufficient for the purposes of this discussion to note that the project achieved its goal of data gathering to support advocacy and campaigning at the UN's biennial progress assessment forum.

As part of its reflection and evaluation, however, the network also considered its broader nature and its communications. It reflected on the initial goal of building a rich community of practice, drawing on ideas such as 'social networks' and making use of the latest ICT communications. There was strong agreement that this goal had not been achieved. In fact, the network's communications had been limited and were predominantly 'hub and spoke' (to and from the central secretariat) rather than 'cat's cradle' (rich communications between peers in the network) (Gibson 2010; Brown \& Gaventa 2008).

The statistics support this finding. Despite, for example, developing and promoting blogs, discussion forums, document stores and messaging on the network's website, the traffic through the site was, for the most part, minimal.

There are occasional spikes in the graph relating to the live publication of blogs and information during the biennial UN conference in June 2009 at which GNDR presented its survey, and to live webstreaming of the GNDR global workshop in January 2010. However, apart from those peaks the average number of hits per day was approximately 20, whilst the active membership signed up to the website was approximately 200 . Therefore in general only $10 \%$ of the membership was using the site from day to day. Other data, such as records of email correspondence and consultation at the Global Workshop, supported the conclusion that there was little communication between peers in the network despite regular promotion and facilitation of communication and discussions.

The author found the fact that network members did not participate in forums, blogs and discussions, or in fact undertake networking in the traditional sense to any great extent, quite frustrating. This had been perceived as a major element of building a distributed network.

Network members were consulted on this at the Global Workshop and they voted on their preferred information and communication channels (the workshop used a keypad voting system for live voting and feedback). The results

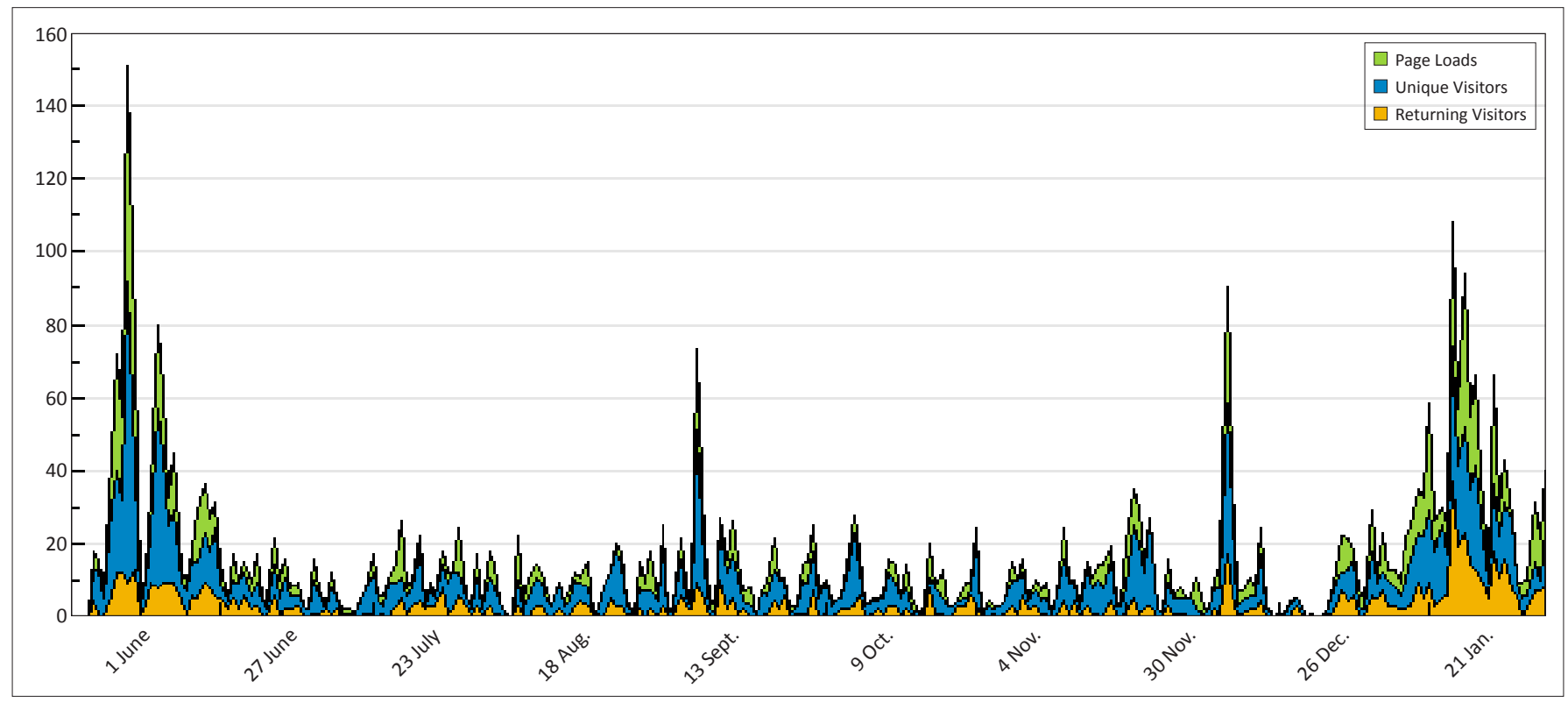

Source: (Gibson, T.D., 2010, 'It's not just the data: Participatory monitoring and the most significant change', paper presented at the 7th International ISCRAM Conference, Seattle, Washington, 03-05 May)

FIGURE 1: Website hits for GNDR website June 2009 - January 2010. 
reflect a preference for face-to-face meetings, email and information stores rather than interactive social networking tools (Figure 2).

However, whilst the networking dimension of the organisation has shown little progress, other activities have been more successful. The Views from the Frontline joint action of the network members generated some interesting and surprising outcomes.

\section{The network's joint action}

The major part of the author's workload was concerned with the Views from the Frontline project. Mobilising participants in 48 countries and generating survey data from over 7000 respondents represented a major success for the network. However, the learning review and discussion led to an emerging awareness that the real nature of the network was rather different from the 'community of practice' model which had been assumed to predominate.

Whilst the network was organised around the Views from the Frontline project, what emerged from the comments of participants during the review phase was the suggestion that this action not only had an 'output impact' (bringing a citizen voice to the attention of the international regime) but also a 'process impact' which many network members were recognising as at least as significant as the first impact.

What was this 'process impact' and why was it important? Members characterised it as the creation of opportunities for discussion and learning between participants and respondents in the survey. Amongst key respondents were local government representatives, civil society organisation representatives and community leaders. These discussions were breaking new ground as long-held suspicions and barriers between these actors appeared to be breaking down. In many cases they had previously had little contact with each other; communities are often suspicious of local government, and local government in turn often has a weak relationship with civil society organisations. However, the encounters initiated by the surveying and consultation process were creating dialogue which led to the participants - the leading staff members of the participating NGOs - identifying new ways of working together and taking joint action. In this regard, Freire (1996:60) succinctly states: 'here, no one teaches another: nor is anyone self-taught. People teach each other; mediated by the world'.

In one instance in Kathmandu, Nepal, for example, local government began to recognise the expertise of the local civil society organisation because of the discussions they had had. As a result they invited the civil society organisation to lead workshops to train their staff, and initiated a communitybased hazard mapping project. In another instance the local civil society organisation in the Niger delta region of Nigeria started a collaboration with local government officials and together they used the Views from the Frontline data to lobby the central government for resources to restore flooddamaged communications.

As the network reflected more widely on these experiences in their review and at the workshop it concluded that the shared action resulted in learning, which in turn was liberating participants to work in ways they had not previously imagined or considered:

The insistence that the oppressed engage in reflection on their concrete situation is not a call to armchair revolution. On the contrary, reflection - true reflection - leads to action. On the

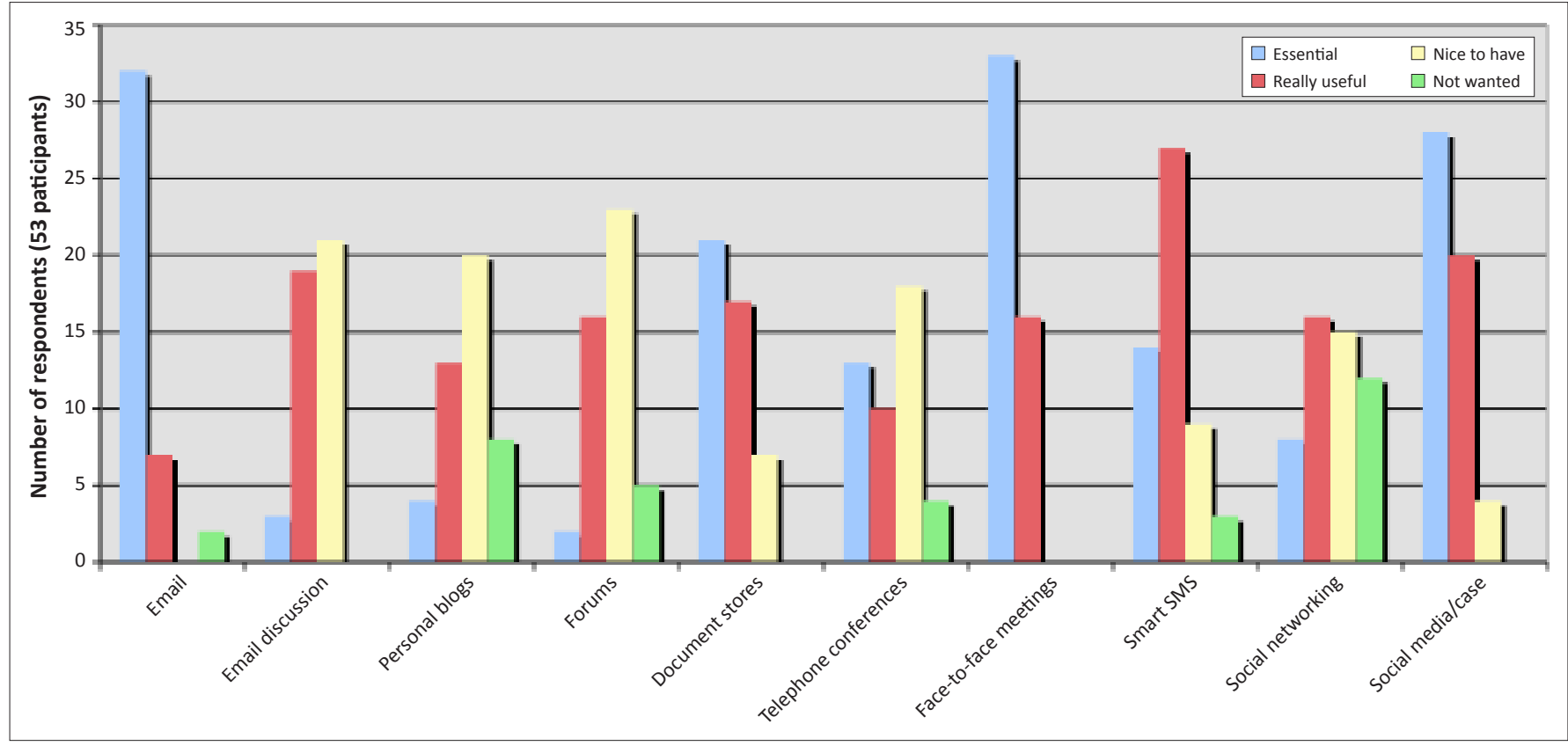

Source: Gibson, T.D., 2010, 'It's not just the data: Participatory monitoring and the most significant change', paper presented at the 7th International ISCRAM Conference, Seattle, Washington, 03-05 May)

FIGURE 2: Assessment of different communication methods. Live poll at Global Workshop January 2010. 
other hand, when the situation calls for action, that action will constitute an authentic praxis only if its consequences become the object of critical reflection. (Freire 1996:48)

The cycles of action and reflection which Freire characterised here were quite different from the programme the network had planned, based on its initial 'community of practice' model. In the case of a community of practice, the participants are normally concerned with their own 'action scene', and form a meta-community to share learning derived from their independent spheres of action. Therefore the emphasis is on building knowledge and information flows to support people working in their own distinct domains. However, in the case of GNDR and the Views from the Frontline project, the emerging focus was on a shared action which created dialogue, partnership and joint action. Gaventa's work on power and participation offers a useful term for this: 'created political spaces' (Gaventa 1980).

\section{'Community of Praxis?'}

At this point we return to Freire (1996). For him, meaningful knowledge is generated from action and reflection in response to oppression, leading to enlightenment and the establishment of new 'spaces' which reconfigure political power. In the network's experience action and reflection were in response to the perceived inability of the international system to take account of civil society's experience and knowledge, as in the example from Nigeria cited above. Furthermore:

A deepened consciousness of their situation leads people to apprehend that situation as an historical reality susceptible of transformation. Resignation gives way to the drive for transformation and inquiry, over which they feel themselves to be in control. (p. 66)

In this case the participative action - initiated by the desire to secure an active and challenging citizen voice at the UN platform - generated new dialogues and collaborations through its execution, which in turn had led to the creation of new spaces, both locally and internationally. It also changed the network members' own perception of their role.

In Freirian terms a cycle of action led in an unexpected way to reflection, transformation and enquiry between the local level actors drawn into dialogue through the survey. A second cycle took place in which the joint action of the network members led to reflection and recognition of a new mode of action. This was shown in terms of impact on the network members' work in the learning reviews conducted by the network in 2009 and 2011, and in terms of external impact in the comment of Margareta Wahlstrom, head of UNIDR, that:

\footnotetext{
... you have clearly through this work and this product moved the agenda forwards considerably. That's an achievement and it also generates a bit of responsibility. (Margareta Wahlstrom's address to the Global Workshop 27 Jan 2010, Part 1)
}

Freire asserts that 'action will constitute an authentic praxis only if its consequences become the object of critical reflection' (1996:48) and this is exactly what happened in the network's discussions. On the one hand there had been very limited information and knowledge flows through the network's email and web channels, but on the other hand its shared action had led to reflection which enabled the network to learn new ways of achieving a transformation of their reality, through stimulating 'praxis' at the local level. For GNDR it appeared that rather than learning happening as a background activity, in the style of a 'community of practice', it resulted from shared action and reflection on that action.

I therefore propose the term 'community of praxis' to describe such a process (Gibson 2011). This will distinguish the behaviour and purpose of such a community from that of a 'community of practice'. The key driver for a community of praxis is not knowledge flows emanating from individual action and practice, but 'knowledge creation' generated from a shared action leading to a shared understanding.

The network's concern over its predominantly 'hub and spoke' nature seems in retrospect to be misplaced. The network's shared action demanded intense coordination which, at least in the first iteration of the Views from the Frontline survey required a 'hub and spoke' network. It is argued here that the network's real character was based on this collaborative shared action embodied in Views from the Frontline rather than on a 'community of practice' structure.

However, the network is clearly a learning-based network. Its learning style depends on a 'social learning' process (see Wals 2007 for examples of similar 'social learning' processes). Its action and reflection rely on communication to achieve joint understanding. While the cycle of joint action followed by collaborative reflection was embedded in the project design, the network did not anticipate that learning and 'knowledge creation' would emerge in such a striking way from this cycle. It now recognises that processes of dialogue must form a greater focus at the local level as it pursues the next phase of its Views from the Frontline project. It also recognises that through reflection on its shared action it undergoes dynamic change in its own character and behaviour. These discoveries reflect the principles of a 'community of praxis'.

The network faces emerging challenges and questions as a result of these dynamic processes:

1. Growth can be a challenge. Compared with the 48 countries embarking on Views from the Frontline in 2009, 70 set out on the 2011 project. Within a larger network relationships are more diffuse.

2. The tight communication and direction necessary to maintain a shared action can militate against peer-to-peer communication, and there is evidence that the 'hub and spoke' nature of the network has become more, rather than less, pronounced.

3. Network members themselves suggest that the governance of the network needs to be reconsidered in order to develop 'ownership' between network members, creating a more clearly democratic structure. 
4. Local and regional collaboration may be strengthened by a shift from a central secretariat to a regional or federal structure.

5. The limits of political action through high-level advocacy are detected in the UN institutional response to the Views from the Frontline reports, which have highlighted the need for local action. There is evidence that the UN system has simply appropriated the language. One document, for example, asserts that the UN is now presenting its own 'views from the frontline':

The Global Assessment Report 2011 recognizes local perspectives and incorporates 'Views from the Frontline' from civil society organizations. (Second announcement of Global Platform for Disaster Reduction 2011, UNISDR, 2011)

This claim was made without any change in institutional or national level behaviour having occurred. Members meeting at the 2011 Global Platform where that announcement was made raised the possibility of direct local action supported by the network; in other words, they were looking for different political 'spaces'.

\section{Conclusions}

Networks and movements are phenomena of our time, driven by the recognition of the need for new social and political configurations and by the enabling factors of communications and mobility. It is suggested here that Freire's work of over forty years ago is highly relevant to learning and action processes within contemporary networks when situated within local groups and culture circles. This case study has shown such a network discovering the power of action and reflection cycles in its Views from the Frontline project, and also in understanding its own character and learning style. It has moved from a 'communities of practice' model to an emerging 'community of praxis' approach which has enabled it to dynamically shape its structure and working methods on the basis of learning emerging from action and reflection.
'Designing in' a praxis-based approach based on this shared action and reflection model is offered for discussion as a tool to enable other networks to dynamically shape their activities.

\section{Acknowledgements Competing interests}

The author declares that he has no financial or personal relationships which may have inappropriately influenced him in writing this article.

\section{References}

Brown, L.D. \& Gaventa, J., 2008, 'Constructing transnational action research networks: Observations and reflections from the case of citizenship DRC, IDS Working Paper 302 ', Institute of Development Studies, Brighton.

Chambers, R., 1997, Whose reality counts? Putting the last first, Intermediate Technology Publications, London.

Cooke, B. \& Kothari, U. (eds.), 2001, Participation: The new tyranny?, Zed Books, London.

Freire, P., 1996, Pegagogy of the Oppressed, rev. edn., Penguin, London.

Gaventa, J., 1980, Power and powerlessness: Quiescence and rebellion in an Appalachian Valley, University of Illinois Press, Champaign.

Gibson, T.D., 2010, 'It's not just the data: Participatory monitoring and the most significant change', paper presented at the 7th International ISCRAM Conference, Seattle, Washington, 03-05 May.

Gibson, T.D., 2011, 'Action and learning in an emerging network', Humanitarian Exchange Magazine 50, April, viewed 25 April 2012, from http://www.odihpn. org/report.asp?id=3208

GNDR (Global Network for Disaster Reduction), 2009, Clouds but little rain: Views from the frontline, Tearfund, Teddington.

Habermas, J., 1987, The theory of communicative action, vol. 2: Lifeworld and system: A critique of functionalist reason, Polity Press, Cambridge.

Kolb, D., 1984, Experiential learning: Experience as the source of learning and development, Prentice-Hall, Englewood Cliffs, NJ.

Margareta Wahlstrom's address to the Global Workshop 27 Jan 2010, Part 1, video recording, viewed 20 August 2012, from http://www.youtube.com/watch?v=FjlAl xDTzoo\&list=UUn7cG1Rj564YbbyFsLpSdzw\&index=2\&feature=plcp

Waddell, S., 2009, 'Global action networks: An organisational innovation', Reflections 9(3/4), 1-14. UNISDR, 2011, email, February.

Wals, A.E.J. (ed.), 2007, Social learning towards a sustainable world, Wageningen Academic Publishers, Wageningen.

Wenger, E., McDermott, R.A. \& Snyder, W.M., 2002, Cultivating communities of practice: A guide to managing knowledge, Harvard Business Publishing, Boston. 